\title{
Website Design and Trust Elements: A/B Testing on a Start-up's Website
}

\author{
Lars Schmitt \\ Technical University of Munich, Germany \\ Isabel Haupenthal \\ Technical University of Munich, Germany \\ Faisal Bin Ahmed \\ Technical University of Munich, Germany
}

\begin{abstract}
Start-ups are young companies that are hardly known, especially during their early stages, by the relevant stakeholders. A start-up's website is, therefore, often the first point of contact for potential customers, investors, or partners. Such a website usually explains the new product or service and presents the founding team with its competencies. The user's perception of the website and its design can be crucial in determining whether the user is interested in getting in touch with the start-up or even considering the purchase of the respective product or service. User's trust in the website and its operator is essential for this. The so-called trust elements, such as logos, testimonials, or seals, are intended to create trust on websites. So far, the influence of these elements on user behaviour has hardly been empirically proven in a real-life context. Therefore, we have applied the method of $A / B$ testing to the website of a fictive start-up. Trust elements were placed on one variant of the website (A), whereas on the other variant, there were none (B). The experiment shows that the duration of the user sessions does not differ between the two variants. However, more requests were made on the website variant with trust elements.
\end{abstract}

Keywords: website design, e-trust, online trust, e-commerce, A/B testing JEL classification: L26, C99

Paper type: Research article

Received: Feb 23, 2021

Accepted: May 15, 2021

DOI: $10.54820 /$ ZOWH5239 


\section{Introduction}

Due to the growing importance of digitalization and the associated increase in using the internet, traditional commerce has become much more digital, what is called electronic commerce or e-commerce (Muñoz-Leiva et al., 2010). E-commerce has changed a lot, particularly in the business-to-consumer sector (B2C), as new possibilities occurred to distribute goods and services directly to the customer (Walia et al., 2013). Companies can use their websites as communication channels (Rahimnia et al., 2013) to offer products and services beyond their offices and shops (Beldad et al., 2010). With the help of these channels, companies can get in touch with existing customers as well as potential new ones (Rahimnia et al., 2013). Furthermore, e-commerce enables significant benefits for businesses and consumers, such as the reduction of costs (Rahimnia et al., 2013). From the perspective of potential customers, websites can be used to satisfy their needs and demands, such as obtaining a new product or service (Kim et al., 2010). Website users can interact and conduct transactions with the supplying party without any temporal or spatial constraints (Beldad et al., 2010; Lowry et al., 2014). Consequently, the purchase of a product or service might be possible under better conditions (Muñoz-Leiva et al., 2010). Hence, an increasing number of customers favor e-commerce over traditional commerce for these reasons (Li et al., 2010).

With a focus on start-ups and young companies, e-commerce facilitates its entry into the global market and enables them to target a high-volume customer base (Rahimnia et al., 2013). In addition, e-commerce reduces marketing costs, promotes closer relationships with business partners as well as with customers, and can thus improve the popularity of the company (Rahimnia et al., 2013). Therefore, successful e-commerce businesses require websites that are visually appealing, easily navigable, informative, and secure (Cyr, 2013).

As e-commerce lacks any kind of typical social presence, many concerns emerge, which cause people to be reluctant when operating online (Beldad et al., 2010). The larger the amount of money, the more concerned customers are about completing an online transaction (Muñoz-Leiva et al., 2010). As fraud also takes place online and e-commerce grows rapidly, one can assume that fraud cases continue to increase immensely (Walia et al., 2013). Therefore, the essential question is raised on how to establish trust in interactions or transactions conducted on the Internet, which is also called "e-trust" (Taddeo, 2009).

Several researchers have already found an answer to this question by identifying various website features and elements that influence users' trust and, consequently, user behavior. These are often called "trust-inducing features" (Wang et al., 2005) or "trust elements" (Sivaji et al., 201 1). However, their effect has hardly been empirically proven and tested in a real-life context. In contrast, laboratory experiments with control groups are much more common in the field of e-trust. We attempt to contribute to the e-trust literature through an experiment using $A / B$ testing in a reallife context, meaning there are at least two variants of the same website. Differences in user behavior become, therefore, apparent in A/B testing. In our case, the website variants differ in the presence of trust elements so that on one variant, trust elements were visible (A), while on the other, these were removed (B). As far as we know, this application of website-based A/B testing in a real-life context is unique in the field of e-trust. 


\section{Theoretical background}

According to Rotter (1967), trust is "the belief that one party will reliably keep its word or promise and fulfill its obligations in an exchange relationship." Gefen et al. (2003) define trust as "the expectations that other individuals or companies with which one interacts will not take improper advantage resulting from the dependence one has on them." Coming from these offline dimensions of trust, Urban et al. (2000) transferred trust concepts to online dimensions by explaining how website trust is built. The authors also point out different contexts in which website trust might be important, e.g., online sales advisors, product presentation, advertising, or pricing (Urban et al., 2000).

Due to the increasing importance of e-commerce, the term "e-trust" was soon introduced (Merrilees et al., 2003) as well as "online trust" (Wang et al., 2005; Kracher et al., 2005). Taddeo (2009) defines e-trust as "trust in digital contexts" and states that it "occurs in environments where direct and physical contacts do not take place, where moral and social pressures can be differently perceived, and where interactions are mediated by digital devices." E-trust is placed in a website and its content when the customer assumes that the other party is reliable and will fulfill its obligations (Muñoz-Leiva et al., 2012). We use the terms - website trust, online trust, and e-trust - as synonyms in the following. Another terminological distinction should nevertheless be made regarding the term "WebTrust". WebTrust represents guidelines for e-commerce assurance services which were developed by the American Institute of Certified Public Accountants, jointly with the Canadian Institute of Chartered Accountants (Chang et al., 2011).

Salam et al. (2003) differentiate between the trustee and the trustor. The trustee represents the party that is being trusted, so the website's operator who offers products or services. Hence, the trustor is the user who places trust in the trustee. Trust between these parties is based on the user's perception of the operator's ability, benevolence, and integrity (Mayer et al., 1995; McKnight et al., 2001; Palvou, 2003). Ability is here defined as the perceived competencies and skills of the website operator (McKnight et al., 2002). Benevolence is described as the degree of empathy that the operator has towards the user, whereas integrity refers to the aspect that the website's operator follows ethical and moral standards. Similar aspects are mentioned by Grabner-Kräuter et al. (2006), who distinguish between a soft and a hard dimension of trust. Soft characteristics of the trusted party are benevolence, honesty, integrity, and credibility, whereas hard characteristics are competence, predictability, reliability, correctness, and availability. Both dimensions affect the trustworthiness and the (perceived) functionality of the trusted party.

Further aspects for assessing the trustworthiness are the operator's reputation, the appearance and design of the website, and its performance (Beldad et al., 2010; Pengnate et al., 2013). It is important to mention as well that potential customers focus heavily on reviews and other persons' feedback, even if they do not know them personally (Beldad et al., 2010). This is because people are "truth-biased", which means that they tend to believe criticism and reviews from other people (Liv et al., 2012). Tamimi et al. (2015) emphasize that more online experience reduces perceived risks. Hence, experienced users are mainly influenced by ratings of reviews and the price of products when making their purchase decision. In contrast, less experienced users perceive the product type as the most important aspect.

Altogether many aspects play a role in the context of e-trust. The main objective from the perspective of the website's operator is to influence the user's purchase and repurchase intention. Lim (2015) states that this intention is influenced by the user's attitude as well as the perceived ease of use of the website. According to 
Zhang et al. (2011), the repurchase intention is closely related to online customer loyalty, which might bring a competitive advantage to the website's operator.

In our study, we focus on website design and, therefore, on trust elements that (might) influence user behavior and e-trust. For this, we use the framework of trustinducing interface design features from Wang et al. (2005). The authors developed this framework based on the existing literature. Furthermore, they categorized the identified trust elements in four dimensions: graphic design, structure design, content design, and social-cue design (see Table 1). Their dimensions were later confirmed by Seckler et al. (2015) through a web-based survey. When filling out the survey, the study's participants should think of an occasion where they felt "exceptionally trustful/distrustful" using a website (Seckler et al., 2015). Consequently, their study relied on participants' memory and prior experiences with websites.

Table 1

Design elements influencing e-trust

\begin{tabular}{|c|c|c|}
\hline Dimension & Explanation & Examples \\
\hline $\begin{array}{l}\text { Graphic } \\
\text { design }\end{array}$ & $\begin{array}{l}\text { Refers to the graphical and visual } \\
\text { design factors on the website that } \\
\text { normally give consumers a first } \\
\text { impression }\end{array}$ & $\begin{array}{l}\text { - Use of three-dimensional dynamic } \\
\text { - Use of moderate pastel colors } \\
\text { - Use of well-chosen photographs }\end{array}$ \\
\hline $\begin{array}{l}\text { Structure } \\
\text { design }\end{array}$ & $\begin{array}{l}\text { Defines the overall organization and } \\
\text { accessibility of displayed information } \\
\text { on the website }\end{array}$ & $\begin{array}{l}\text { - Implementation of easy-to-use } \\
\text { navigation, i.e., simplicity and } \\
\text { consistency } \\
\text { - Use of accessible information, e.g., } \\
\text { no broken links } \\
\text { - Application of page design } \\
\text { techniques, e.g., white spaces, } \\
\text { grouping, visual density }\end{array}$ \\
\hline $\begin{array}{l}\text { Content } \\
\text { design }\end{array}$ & $\begin{array}{l}\text { Refers to the informational } \\
\text { components that can be included } \\
\text { on the website, either textual or } \\
\text { graphical }\end{array}$ & $\begin{array}{l}\text { Display of brand-promoting } \\
\text { information, e.g., company logo, } \\
\text { slogan } \\
\text { Up-front disclosure of all aspects of } \\
\text { the customer relationship, e.g., } \\
\text { financial, legal concerns } \\
\text { Display of seals of approval or third- } \\
\text { party certificate } \\
\text { Use of comprehensive and correct } \\
\text { product information }\end{array}$ \\
\hline $\begin{array}{l}\text { Social-cue } \\
\text { design }\end{array}$ & $\begin{array}{l}\text { Relates to embedding social cues, } \\
\text { such as face-to-face interaction and } \\
\text { social presence, into web interface } \\
\text { via different communication media }\end{array}$ & $\begin{array}{l}\text { - Inclusion of a representative } \\
\text { - } \quad \text { Use of synchronous communication } \\
\text { media, e.g., messaging and chat } \\
\text { tools, video telephony }\end{array}$ \\
\hline
\end{tabular}

Source: Wang et al. (2005)

\section{Methodology}

Two research fields are in particular relevant in the context of this study which has not yet been brought together, although they could enrich each other in our opinion. On the one hand, there are practitioners and researchers in the field of A/B testing who mostly present and discuss the methodology (Hynninen et al., 2014; Langmann, 2018) or provide practical business examples (Kohavi et al., 2007; Crook et al., 2009; Kohavi et al., 2011; Kohavi, 2012; Kohavi et al., 2012; Kohavi et al., 2014; Kohavi, 2015). Practitioners usually keep the results of experiments within their company 
scope. On the other hand, we have numerous theoretical models and concepts in the field of e-trust (see pp. 2-3), which were mostly derived from "offline" trust research and have not yet been tested in a real online environment. We are convinced that the method of $A / B$ testing can be used to verify and expand existing theories.

A/B testing has so far mainly been used in practice to improve the website design and to encourage a certain user behavior, e.g., at companies like Airbnb, Amazon, Facebook, Linked In, or Netflix (Kohavi et al., 2020). According to Kohavi et al. (2017), the experimenter normally creates two experiences in A/B testing: "A" usually represents the current website, often considered as the "champion", whereas " $B$ " includes a modification of " $A$ " and can, therefore, be considered as the "challenger". Modifications can be changes regarding the user interface or website layout as well as the implementation of a new website feature. The users are randomly assigned to the two variants, usually with a 50/50 ratio. The key metrics are collected, computed, and analyzed (see Table 2).

Table 2

Selection of typical metrics in an A/B testing

\begin{tabular}{|c|c|}
\hline Metrics & Description \\
\hline Pageviews & $\begin{array}{l}\text { The total number of pages viewed. Repeated views of a single page are } \\
\text { counted }\end{array}$ \\
\hline $\begin{array}{l}\text { Session } \\
\text { duration }\end{array}$ & $\begin{array}{l}\text { Length of a session in seconds. A session lasts as long as there is continued } \\
\text { activity }\end{array}$ \\
\hline Bounces & The total number of single-page visits \\
\hline Transactions & The total number of completed purchases on the website \\
\hline Revenue & The total revenue from web transactions \\
\hline $\begin{array}{l}\text { Click-Through } \\
\text { Rate (CTR) }\end{array}$ & $\begin{array}{l}\text { The rate is calculated by dividing the total number of clicks on an element, } \\
\text { e.g., buttons, by the number of people who have seen the element }\end{array}$ \\
\hline $\begin{array}{l}\text { Conversion } \\
\text { Rate }\end{array}$ & $\begin{array}{l}\text { The rate that is calculated by dividing the total number of conversions by } \\
\text { the total number of visitors, e.g., an e-commerce website receives } 200 \\
\text { visitors/month and has } 50 \text { sales; the conversion rate would be } 50 \text { divided by } \\
200 \text {, or } 25 \%\end{array}$ \\
\hline
\end{tabular}

Sources: Google Optimize (2020); Optimizely (2020)

\section{Experiment}

We have chosen the start-up context as the overall setting of our experiment. The reason for this is that we believe that the website of a young company is of particular importance, as a variety of stakeholders is usually addressed, such as customers, investors, or partners. At the same time, start-ups are hardly known, so that the website becomes, metaphorically speaking, a storefront. Consequently, we created a fictive start-up and the corresponding website with two variants, A and B. The startup was called SECUPROTECT.

The idea of the start-up was a "platform for security services", which was accessible via the following URL: wWW.secuprotect.de. Private and commercial customers could therefore find the right security service provider more quickly with the help of SECUPROTECT. The market for security services is very fragmented. This means that there are many small providers, most of whom are active locally or regionally. It is, therefore, a market where a platform business model potentially makes sense and might bring value for the customer. The fictitious service portfolio of SECUPROTECT included the following security services: object protection (private), object protection (commercial), event protection, and personal protection (see Figure 1). 
Figure 1

Screenshot of the SECUPROTECT website

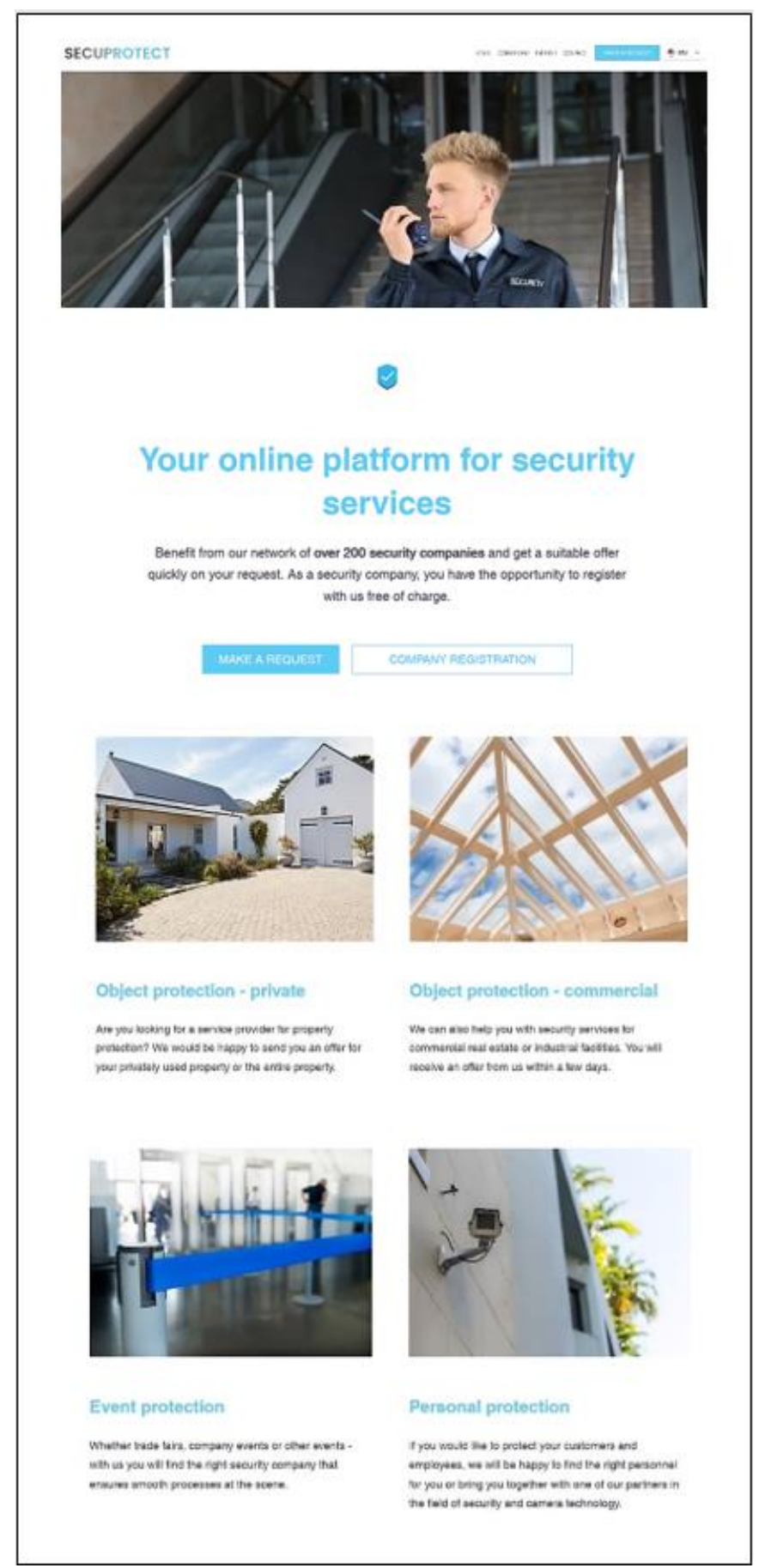

Source: Authors' work

In our experiment, we assume that user's trust has an impact on the mentioned key metrics, especially regarding session duration. More precisely, we assume that users who trust a website stay longer on it and also show a different click behavior, i.e. users click more. Our website variants differ in the presence of trust elements, so on one variant trust elements were visible (A), while on the other these were removed (B). We have decided on three trust elements (see Figure 2): (i) Logos of the (pretended) network of security service providers; (ii) (Fake) Testimonial of a 
customer, and (iii) Linkedln buttons (possibility to check the authenticity of the startup founders).

Figure 2

Screenshot of the trust elements on variant A (removed on variant B)

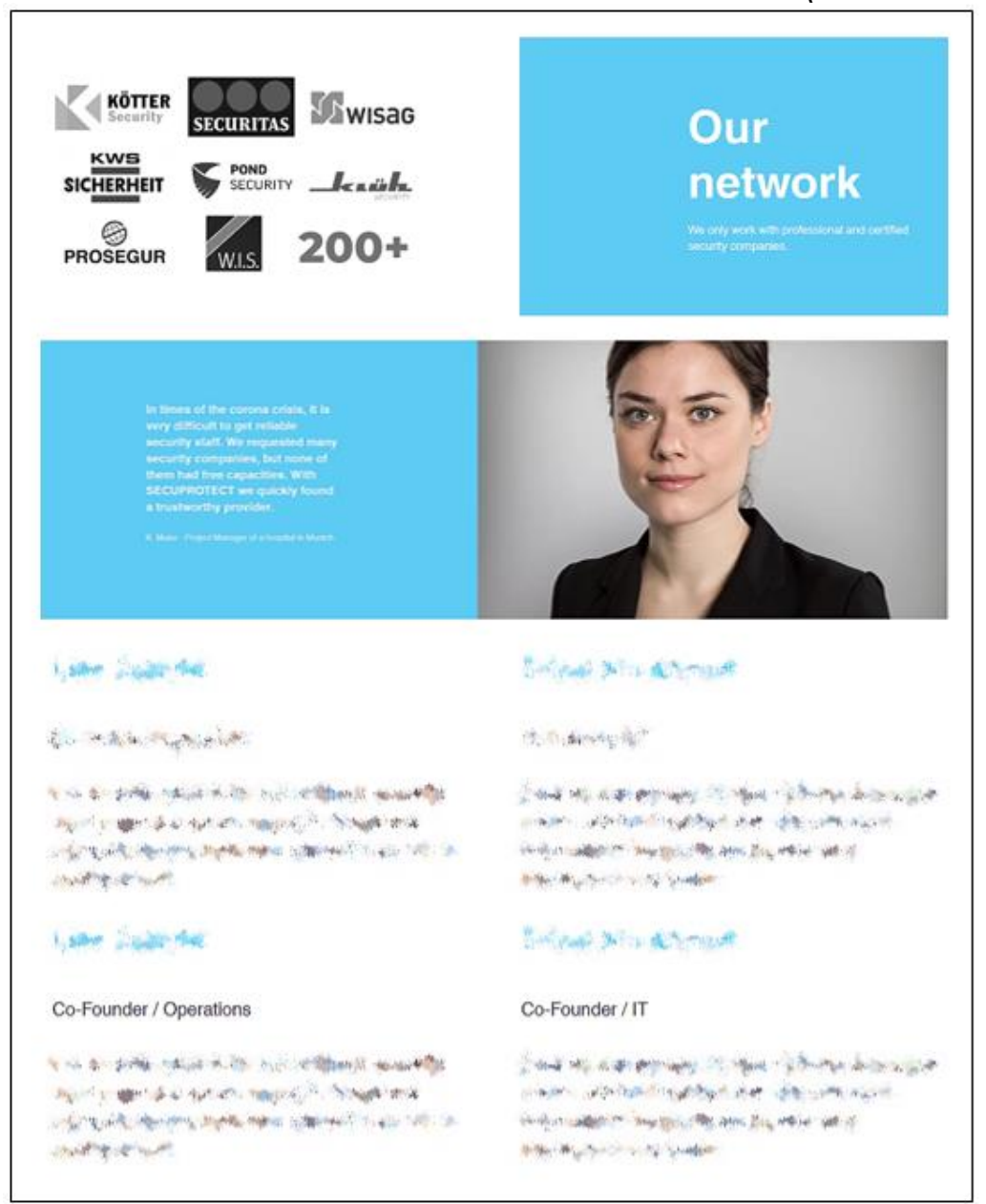

Source: Authors' work

A/B testing should be scheduled for a specific time frame. We have chosen a data collection period of 90 days (May 11, 2020, till August 9, 2020). Meanwhile, we also started the Google Ads campaign to make users aware of our website. Under the keyword "find security services" (German: Sicherheitsdienstleistungen finden) the website appeared mostly on page one or two in the German Google search during the campaign (see Figure 3).

Figure 3

Illustration of the Google advertisement in the German language

Anzeige - www.secuprotect.de/ $v$

Sicherheitsfirma online finden | schnell ein Angebot erhalten

Stellen Sie direkt eine Online-Anfrage für Objektschutz, Eventschutz oder Personenschutz.

Secuprotect ist Ihr Online-Vermittler für Sicherheitsdienstleistungen.

Source: Authors' work

\section{Technical and methodical limitations}

We used the free version of Google Optimize for our experiment which comes with some limitations. In our case, the primary goal was to track the session duration as 
well as the number of clicks on a particular button. While Google Optimize does not support click counts on links or buttons, we decided to use a link shortener service called Cuttly as a workaround. With Cuttly, it is possible to track links or button clicks for free. We created two unique custom links for the same button, so one for each variant. We did this for the button named "Make a request."

Much more problematic from a scientific point of view, was that Google Optimize or Google Analytics does not allow to export of the raw data of the experiment. This is only possible with Google Analytics 360, which we were not aware of before and during the experiment. The use of Google Analytics 360 comes with an annual fee of EUR 135,000 which was of course outside the budget for this project. This also has consequences for the methodology of this study since without raw data no own statistical analyses can be conducted, e.g., t-test. For this reason, the following results are based entirely on Google tools.

\section{Results}

According to the statistics from Google Optimize, there were a total of 456 sessions during the 90-day testing phase, which corresponds to the number of visits. The number of visits has to be distinguished from the number of visitors. The number of visitors was 398, meaning that some users have visited the website again. These were most likely the users who either made a request or registered as a security company. Of 456 sessions, 238 sessions are allocated to variant $A$ and 218 to variant B. On average, users spent 36 seconds on variant $A$ and 31 seconds on variant $B$ (see Table 3). The trust elements, therefore, had no substantial influence on the length of stay.

Table 3

Comparison between variant $A$ and $B$ regarding the session duration

\begin{tabular}{ccccc}
\hline & Sessions & $\begin{array}{c}\text { Total Session } \\
\text { Duration }\end{array}$ & $\begin{array}{c}\text { Calculated Duration per } \\
\text { Session }\end{array}$ \\
\hline $\begin{array}{c}\text { Variant A (with trust } \\
\text { elements) }\end{array}$ & 238 & $02: 20: 53$ (hh:mm:ss) & $00: 00: 36$ & (hh:mm:ss) \\
$\begin{array}{c}\text { Variant B }(\underline{\text { no }} \text { trust } \\
\text { elements) }\end{array}$ & 218 & $01: 52: 20$ (hh:mm:ss) & $00: 00: 31 \quad$ (hh:mm:ss) \\
\hline
\end{tabular}

Source: Authors' work

Regarding the number of clicks on the request button, there was a considerable difference between the two variants. In variant $A$, the request button was clicked 41 times, and we received five real requests. In variant $B$, in comparison, 26 clicks were made on the button, and no requests were submitted (see Table 4). Consequently, the trust elements on variant A led to more requests.

Table 4

Comparison between variant $A$ and $B$ regarding the requests

\begin{tabular}{ccc}
\hline & $\begin{array}{c}\text { Number of Clicks on } \\
\text { Request Button }\end{array}$ & $\begin{array}{c}\text { Number of Requests } \\
\text { Made }\end{array}$ \\
\hline $\begin{array}{c}\text { Variant A (with trust } \\
\text { elements) }\end{array}$ & 41 & 5 \\
$\begin{array}{c}\text { Variant B (no trust } \\
\text { elements) }\end{array}$ & 26 & 0 \\
\hline
\end{tabular}

Source: Authors' work 


\section{Conclusion and outlook}

With our study, we attempt to contribute to the field of e-trust by showing that $A / B$ testing can verify and extend given theories. The experiment has shown that in our case the presence of trust elements did not enhance the user's session duration. This was practically the same between the two variants. The experimental setting has shown as well that more requests were made on the variant with trust elements. It is, therefore, reasonable to conclude that trust elements have a positive influence on user behavior. This has not yet been scientifically proven in the form of A/B testing in a real-life context, which is our contribution.

With the scientific application of the A/B testing in such a real market situation, we have entered the new ground. However, we are aware that this study still leaves some potential untapped. The technical solutions we chose were not optimal in many respects. Thus, for the replication of our experiment, we would recommend using commercial solutions that offer a higher functionality as well as more possibilities to collect and especially to export data. Heat maps are, in this context, an interesting data collection method as well, which might lead to further insights within A/B testing. The respective raw data should always be available. Also, the duration of the experiment and thus the duration of the Google Ads campaign should ideally last longer. If the budget allows it, the mentioned points should be taken into account for similar experimental settings. In addition, ethical standards should also be considered, as we did not inform the participants of the study or ask for their permission. However, it should also be said that companies collect data about our user behavior every day, basically without us knowing the exact use of this data.

Furthermore, it would also be interesting to implement such a research project together with an established company. Thereby, the problem is often that results may not be published. This should be clarified in advance. Consequently, we would be pleased to provide both scientists' and practitioners' orientation and guidance through our study and its shortcomings. Furthermore, we would like to encourage the application of practice-driven methods to scientific questions in the field of humancomputer interaction.

\section{References}

1. Beldad, A., Jong, M., Steehouder, M. (2010), "How shall I trust the faceless and the intangible? A literature review on the antecedents of online trust", Computers in Human Behavior, Vol. 26 No. 5, pp. 857-869.

2. Chang, R.-D., Fang, C.-J., Tseng, Y.-C. (2011), "The effects of WebTrust assurance on consumers' web purchase decisions", Online Information Review, Vol. 36 No. 2, pp. 218240.

3. Crook, T., Frasca, B., Kohavi, R., Longbotham, R. (2009), "Seven pitfalls to avoid when running controlled experiments on the web", Proceedings of the 15th ACM SIGKDD international conference on Knowledge discovery and data mining, pp. 1105-1114.

4. Cyr, D. (2013), "An eight country investigation", Electronic Commerce Research and Applications, Vol. 12 No. 6, pp. 373-385.

5. Gefen, D., Karahanna, E., Straub, D. W. (2003), "Inexperience and experience with online stores: The importance of tam and trust", IEEE Transactions on Engineering Management, Vol. 50 No. 3, pp. 307-321.

6. Google Optimize (2020), "Optimize Resource Hub", available at: https://support.google.com/optimize/answer/7018998?hl=en (15 May 2021) 
7. Grabner-Kräuter, S., Kaluscha, E. A., Fladnitzer, M. (2006), "Perspectives of online trust and similar constructs - a conceptual clarification", Proceedings of the 8th international conference on Electronic commerce, pp. 235-243.

8. Hynninen, P., Kaupinnen, M. (2014), "A/B Testing - A promising tool for customer value evaluation", IEEE 1st International Workshop on Requirements Engineering and Testing, pp. 16-17.

9. Kim, J. U., Kim, W. J., Park, S. C. (2010), "Consumer perceptions on web advertisements and motivation factors to purchase in the online shopping", Computers in Human Behavior, Vol. 26 No. 5, pp. 1208-1222.

10. Kohavi R. (2012), "Online controlled experiments: introduction, learnings, and humbling statistics", Proceedings of the sixth ACM conference on Recommender systems, pp. 1-2.

11. Kohavi, R. (2015), "Online Controlled Experiments: Lessons from Running A/B/n Tests for 12 Years", Proceedings of the 21 th ACM SIGKDD International Conference on Knowledge Discovery and Data Mining, p. 1.

12. Kohavi, R., Deng, A., Frasca, B., Longbotham, R., Walker, T., Xu, Y. (2012), "Trustworthy online controlled experiments: five puzzling outcomes explained", Proceedings of the 18th ACM SIGKDD international conference on Knowledge discovery and data mining, pp. 786-794.

13. Kohavi, R., Deng, A., Longbotham, R., XU, Y. (2014), "Seven rules of thumb for web site experimenters", Proceedings of the 20th ACM SIGKDD international conference on Knowledge discovery and data mining, pp. 1857-1866.

14. Kohavi, R., Henne, R. M., Sommerfield, D. (2007), "Practical guide to controlled experiments on the web: listen to your customers not to the hippo", Proceedings of the 13th ACM SIGKDD international conference on Knowledge discovery and data mining, pp. 959-967.

15. Kohavi, R., Longbotham, R. (2011), "Unexpected results in online controlled experiments", ACM SIGKDD Explorations Newsletter, Vol. 12 No. 2, pp. 31-35.

16. Kohavi, R., Tang, D., Xu, Y., Hemkens L. G., loannidis, J. (2020), "Online randomized controlled experiments at scale: lessons and extensions to medicine", Trials, Vol. 21 No. 1, pp. 1-9.

17. Kohavi, R., Thomke, S. (2017), "The surprising power of online experiments: Getting the most out of A/B and other controlled tests", Harvard Business Review, Vol. 95 No. 5, pp. 7482.

18. Kracher, B., Corritore, C., Wiedenbeck, S. (2005), "A foundation for understanding online trust in electronic commerce", Journal of Information, Communication and Ethics in Society, Vol. 3 No. 3, pp. 131-141.

19. Langmann, S. (2018), "A/B testing - The importance of significance and test duration", Applied Marketing Analytics, Vol. 4 No. 2, pp. 149-156.

20. Li, Y.-M., Yeh, Y.-S. (2010), "Increasing trust in mobile commerce through design aesthetics", Computers in Human Behavior, Vol. 26 No. 4,pp. 673-684.

21. Lim, W. M. (2015), "Antecedents and consequences of e-shopping: an integrated model", Internet Research, Vol. 25 No. 2, pp. 184-217.

22. Liu, B. Q., Goodhue, D. L. (2012), "Two Worlds of Trust for Potential E-Commerce Users: Humans as Cognitive Misers", Information Systems Research, Vol. 23 No. 4, pp. 1246-1262.

23. Lowry, P. B., Twyman, N. W., Pickard, M., Jenkins, J. L., Bui, Q. N. (2014), "Proposing the Affect-Trust Infusion Model (ATIM) to explain and predict the influence of high and low affect infusion on Web vendor trust", Information and Management, Vol. 51 No. 5, pp. 579-594.

24. Mayer, R. C., Davis, J. H., Schoorman, F. D. (1995), "An Integrative Model of Organizational Trust", The Academy of Management Review, Vol. 20 No. 3, pp. 709-734.

25. McKnight, D. H., Chervany, N. L. (2001), "What trust means in e-commerce customer relationship: An interdisciplinary conceptual typology", International Journal of Electronic Commerce, Vol. 6 No. 2, pp. 35-59.

26. McKnight, D. H., Choudhury, V., Kacmar, C. (2002), "The impact of initial consumer trust on intentions to transact with a web site: A trust building model", Journal of Strategic Information Systems, Vol. 11 No. 3-4, pp. 297-323. 
27. Merrilees, B., Fry, M.-L. (2003), "E-trust - the influence of perceived interactivity on eretailing users", Marketing Intelligence and Planning, Vol. 21 No. 2, pp. 123-128.

28. Muñoz-Leiva, F., Hernández-Méndez, J., Sánchez-Fernández, J. (2012), "Generalising user behaviour in online travel sites through the Travel 2.0 website acceptance model", Online Information Review, Vol. 36 No. 6, pp. 879-902.

29. Muñoz-Leiva, F., Luque-Martínez, T., Sánchez-Fernández, J. (2010), "How to improve trust toward electronic banking", Online Information Review, Vol. 34 No. 6, pp. 907-934.

30. Optimizely (2020), "Optimization Glossary", available at: https://www.optimizely.com/optimization-glossary/ (15 May 2021)

31. Palvou, P. A. (2003), "Consumer acceptance of electronic commerce: Integrating trust and risk with the technology acceptance model", International Journal of Electronic Commerce, Vol. 7 No. 3, pp. 101-134.

32. Pengnate, S., Antonenko, P. (2013), "A Multimethod Evaluation of Online Trust and lts Interaction with Metacognitive Awareness: An Emotional Design Perspective", International Journal of Human-Computer Interaction, Vol. 29 No. 9, pp. 582-593.

33. Rahimnia, F., Hassanzadeh, J. F. (2013), "The impact of website content dimension and etrust on e-marketing effectiveness: The case of Iranian commercial saffron corporations", Information and Management, Vol. 50 No. 5, pp. 240-247.

34. Rotter, J. B. (1967), "A new scale for the measurement of interpersonal trust", Journal of personality, Vol. 35 No. 4, pp. 651-665.

35. Salam, A. F., Rao, H. R., Pegels, C. C. (2003), "Consumer-perceived risk in ecommerce transactions", Communications of the ACM, Vol. 46 No. 12, pp. 325-331.

36. Seckler, M., Heinz, S., Forde, S., Tuch, A. N., Opwis, K. (2015), "Trust and distrust on the web - User experiences and website characteristics", Computers in Human Behavior, Vol. 45, pp. 39-50.

37. Sivaji, A., Downe, A. G., Mazlan, M. F., Soo, S.-T., Abdullah, A. (2011), "Importance of incorporating fundamental usability with social and trust elements for E-Commerce website", Proceedings of the International Conference on Business, Engineering and Industrial Applications, pp. 221-226.

38. Taddeo, M. (2009), "Defining Trust and E-Trust - From old theories to new problems", International Journal of Technology and Human Interaction, Vol. 5 No. 2, pp. 23-35.

39. Tamimi, N., Sebastianelli, R. (2015), "The relative importance of e-tailer website attributes on the likelihood of online purchase", Internet Research, Vol. 25 No. 2, pp. 169-183.

40. Urban, G. L., Sultan, F., Qualls, W. J. (2000), "Placing trust at the center of your internet strategy", MIT Sloan Management Review, Vol. 42 No. 1, pp. 39-48.

41. Walia, N., Zahedi, F. M. (2013), "Success Strategies and Web Elements in Online Marketplaces: A Moderated-Mediation Analysis of Seller Types on eBay", IEEE Transactions on Engineering Management, Vol. 60 No. 4, pp. 763-776.

42. Wang, Y. D., Emurian, H. H. (2005), "An overview of online trust: Concepts, elements and implications", Computers in Human Behavior, Vol. 21 No. 1, pp. 105-125.

43. Zhang, Y., Fang, Y., Wei, K.-K., Ramsey, E., McCole, P., Chen, H. (2011), "Repurchase intention in B2C e-commerce - A relationship quality perspective", Information and Management, Vol. 48 No. 6, pp. 192-200. 


\section{About the authors}

Lars Schmitt is a PhD student at the Technical University Munich (GER) as the Chair of Innovation Economics. He is a graduate of the master's in General Management of the Zeppelin University Friedrichshafen (GER). The author can be contacted at lars.schmitt@łum.de

Isabel Haupenthal is a graduate of the Technical University of Munich. She wrote her final thesis at the Chair for the Economics of Innovation. The author can be contacted at isabel.haupenthal@gmx.de

Faisal Bin Ahmed is a graduate of the TUM Department for Informatics. The author can be contacted at faisalbin@outlook.com 